\title{
Breast Cancer Resistance Protein and P-Glycoprotein Influence In Vivo Disposition of ${ }^{11} \mathrm{C}$-Erlotinib
}

\author{
Alexander Traxl ${ }^{1}$, Thomas Wanek ${ }^{1}$, Severin Mairinger ${ }^{1}$, Johann Stanek ${ }^{1,2}$, Thomas Filip ${ }^{1}$, Michael Sauberer ${ }^{1}$, \\ Markus Müller ${ }^{2}$, Claudia Kuntner ${ }^{1}$, and Oliver Langer ${ }^{1,2}$ \\ ${ }^{1}$ Health and Environment Department, AIT Austrian Institute of Technology GmbH, Seibersdorf, Austria; and ${ }^{2}$ Department of Clinical \\ Pharmacology, Medical University of Vienna, Vienna, Austria
}

\begin{abstract}
${ }^{11} \mathrm{C}$-erlotinib is a PET tracer to distinguish responders from nonresponders to epidermal growth factor receptor-targeted tyrosine kinase inhibitors and may also be of interest to predict distribution of erlotinib to tissues targeted for treatment. The aim of this study was to investigate if the known interaction of erlotinib with the multidrug efflux transporters breast cancer resistance protein (humans, ABCG2; rodents, Abcg2) and P-glycoprotein (humans, ABCB1; rodents, Abcb1a/b) affects tissue distribution and excretion of ${ }^{11} \mathrm{C}$-erlotinib and has an influence on the ability of ${ }^{11} \mathrm{C}$-erlotinib PET to predict erlotinib tissue distribution at therapeutic doses. Methods: Wild-type and Abcb1a/b or Abcg2 knockout mice underwent ${ }^{11} \mathrm{C}$-erlotinib PET/MR scans, with or without the coinjection of a pharmacologic dose of erlotinib $(10 \mathrm{mg} / \mathrm{kg})$ or after pretreatment with the ABCB1/ABCG2 inhibitor elacridar $(10 \mathrm{mg} / \mathrm{kg})$. Integration plot analysis was used to determine organ uptake ( $\left.\mathrm{CL}_{\text {uptake}}\right)$ and biliary excretion $\left(\mathrm{CL}_{\text {bile }}\right.$ ) clearances of radioactivity. Results: ${ }^{11} \mathrm{C}$-erlotinib distribution to the brain was restricted by Abcb1a/b and Abcg2, and $\mathrm{CL}_{\text {uptake }}$ into the brain was only significantly increased when both $\mathrm{Abcb} 1 \mathrm{a} / \mathrm{b}$ and Abcg2 were absent (wild-type mice, $0.017 \pm 0.004 \mathrm{~mL} / \mathrm{min} / \mathrm{g}$ of tissue; Abcb1a/b/(-) $\mathrm{Abcg}^{(-/-)}$mice, $0.079 \pm 0.013 \mathrm{~mL} / \mathrm{min} / \mathrm{g}$ of tissue; $P<$ $0.001)$. The pretreatment of wild-type mice with elacridar increased $\mathrm{CL}_{\text {uptake }}$ into the brain to levels comparable to Abcb1a/b(-/) $\mathrm{Abcg} 2^{(-/)}$ mice $(0.090 \pm 0.007 \mathrm{~mL} / \mathrm{min} / \mathrm{g}$ of tissue, $P<0.001)$. The absence of Abcb1a/b and Abcg2 led to a 2.6-fold decrease in $\mathrm{CL}_{\text {bile }}$ (wild-type mice, $0.025 \pm 0.005 \mathrm{~mL} / \mathrm{min} / \mathrm{g}$ of tissue; Abcb1a/b(-/) $\mathrm{Abcg} 2^{(-/)}$mice, $0.0095 \pm 0.001 \mathrm{~mL} / \mathrm{min} / \mathrm{g}$ of tissue; $P<0.001$ ). There were pronounced differences in distribution of ${ }^{11} \mathrm{C}$-erlotinib to the brain, liver, kidney, and lung and hepatobiliary excretion into intestine between animals injected with a microdose and pharmacologic dose of erlotinib. Conclusion: $A B C G 2, A B C B 1$, and possibly other transporters influence in vivo disposition of ${ }^{11} \mathrm{C}$-erlotinib and thereby affect its distribution to normal and potentially also tumor tissue. Saturable transport of erlotinib leads to nonlinear pharmacokinetics, possibly compromising the prediction of erlotinib tissue distribution at therapeutic doses from PET with a microdose of ${ }^{11} \mathrm{C}$-erlotinib. The inhibition of $\mathrm{ABCB} 1$ and $\mathrm{ABCG} 2$ is a promising approach to enhance brain distribution of erlotinib to increase its efficacy in the treatment of brain tumors.
\end{abstract}

Key Words: ${ }^{11} \mathrm{C}$-erlotinib; PET; breast cancer resistance protein; P-glycoprotein; nonlinear pharmacokinetics

J Nucl Med 2015; 56:1930-1936

DOI: 10.2967/jnumed.115.161273

Received May 27, 2015; revision accepted Aug. 31, 2015.

For correspondence or reprints contact: Oliver Langer, Health and Environment Department, AIT Austrian Institute of Technology GmbH, 2444 Seibersdorf, Austria.

E-mail: oliver.langer@ait.ac.at

Published online Sep. 10, 2015.

COPYRIGHT (C 2015 by the Society of Nuclear Medicine and Molecular Imaging, Inc.
$\mathbf{E}$ rmal growth factor receptor (EGFR) that has been approved for treatment of advanced, metastatic non-small cell lung cancer (NSCLC) and advanced, unresectable, or metastatic pancreatic cancer. Approximately $10 \%$ of NSCLC patients in the Western population harbor an activating mutation in their EGFR genes (e.g., the exon 19 deletion delE746-A750 or the exon 21 point mutation L858R) resulting in higher response rates to treatment with erlotinib or gefitinib, another EGFR-inhibiting TKI, as compared with patients with wild-type EGFR (1). ${ }^{11} \mathrm{C}$-erlotinib has been proposed as a PET tracer to distinguish erlotinib-sensitive from erlotinibresistant NSCLC patients (2,3). In preclinical PET studies, higher uptake of ${ }^{11} \mathrm{C}$-erlotinib was found in tumor xenografts with activating EGFR mutations (e.g., delE746-A750, L858R) than in tumor xenografts expressing wild-type EGFR or EGFR with secondary resistance causing mutations (exon 20 missense mutation T790 M) $(2,4-6)$. It has been hypothesized that the binding affinity of ${ }^{11} \mathrm{C}$-erlotinib is higher to EGFR with activating mutations than to wild-type EGFR, resulting in a higher PET signal (3). In NSCLC patients, it was shown that the distribution volume of ${ }^{11} \mathrm{C}$-erlotinib was significantly higher in tumors with an exon 19 deletion than in tumors with wild-type EGFR (3). Apart from visualizing the EGFR mutational status of tumors, ${ }^{11} \mathrm{C}$-erlotinib PET may also be of interest to predict the distribution of erlotinib to different body tissues targeted for erlotinib treatment (e.g., lung, brain, liver).

Erlotinib undergoes extensive metabolism in humans and is mainly excreted via the hepatobiliary pathway (7). Erlotinib is a substrate (8) and inhibitor (9) of the adenosine triphosphate-binding cassette $(\mathrm{ABC})$ transporters breast cancer resistance protein (humans, ABCG2; rodents, Abcg2) and P-glycoprotein (humans, $\mathrm{ABCB} 1$; rodents, $\mathrm{Abcb} 1 \mathrm{a} / \mathrm{b}$ ), resulting in a low extent of brain distribution due to ABCG2- and ABCB1-mediated efflux transport at the blood-brain barrier (BBB) $(8,10,11)$. Apart from the $\mathrm{BBB}$, $\mathrm{ABCB} 1$ and $\mathrm{ABCG} 2$ are also expressed in excretory organs, such as liver and kidney, in which they mediate excretion of drugs and their metabolites into bile and urine, respectively (12). For the future diagnostic use of ${ }^{11} \mathrm{C}$-erlotinib as a PET tracer in tumor patients it is important to understand the influence of $\mathrm{ABCB} 1$ and ABCG2 on organ distribution and excretion of ${ }^{11} \mathrm{C}$-erlotinib as patients may undergo ${ }^{11} \mathrm{C}$-erlotinib PET scans both without and with concomitant treatment with therapeutic doses of erlotinib, possibly leading to partial saturation of $\mathrm{ABCB} 1$ and $\mathrm{ABCG} 2$ causing changes in tissue distribution. Moreover, ABCG2 and ABCB1 may be overexpressed in multidrug-resistant tumors and thereby influence tumor distribution of ${ }^{11} \mathrm{C}$-erlotinib (13). 
In the present study, we performed small-animal PET/MR experiments with ${ }^{11} \mathrm{C}$-erlotinib without and with the coinjection of a pharmacologic dose of erlotinib in wild-type and Abcb1a/b or Abcg2 knockout mice to assess the influence of these transporters on ${ }^{11} \mathrm{C}$-erlotinib organ distribution and excretion. We hypothesized that partial transporter saturation at therapeutic doses may lead to nonlinear pharmacokinetics of ${ }^{11} \mathrm{C}$-erlotinib and failure of a PET microdose to predict the organ distribution of a therapeutic dose.

\section{MATERIALS AND METHODS}

\section{Chemicals}

Elacridar hydrochloride (Syncom BV) was freshly dissolved before each administration in propylene glycol/dimethyl sulfoxide/physiologic saline $(40 / 30 / 30, \mathrm{v} / \mathrm{v} / \mathrm{v})$ and injected intravenously at a volume of $2 \mathrm{~mL} / \mathrm{kg}$ of body weight. Erlotinib hydrochloride (Apollo Scientific Ltd.) was freshly dissolved before each administration in $10 \%$ (v/v) aqueous ethanol solution and injected intravenously at a volume of $4 \mathrm{~mL} / \mathrm{kg}$ of body weight.

\section{Animals}

Female wild-type, Abcb1a/b $\mathrm{b}^{(-/-)}$, Abcg $2^{(-/-)}$, and Abcb1a/b $\mathrm{b}^{(-/-)}$ $\operatorname{Abcg} 2^{(-1-)}$ mice with a FVB genetic background were obtained from Charles River and Taconic Biosciences Inc. At the time of experiment, animals were $10-15$ wk old and weighed $25 \pm 2 \mathrm{~g}$. All animal experiments were approved by the national authorities (Amt der Niederösterreichischen Landesregierung) and all study procedures were performed in accordance with the European Communities Council Directive of September 22, 2010 (2010/63/EU).

\section{Radiotracer Synthesis}

${ }^{11} \mathrm{C}$-erlotinib was synthesized as described before (3) with a radiochemical purity more than $98 \%$ and a specific activity of $47.9 \pm 64.1$ $\mathrm{GBq} / \mu \mathrm{mol}(n=29) .{ }^{11} \mathrm{C}$-erlotinib was formulated in $0.1 \mathrm{mM}$ hydrochloric acid in physiologic saline at an approximate concentration of $370 \mathrm{MBq} / \mathrm{mL}$ for intravenous injection into animals.

\section{Experimental Design}

Groups of wild-type, Abcb1a/ $\mathrm{b}^{(-/-)}, \mathrm{Abcg} 2^{(-/-)}$, and Abcb1a/b $\mathrm{b}^{(--)}$ $\operatorname{Abcg} 2^{(-1-)}$ mice $(n=4$ per group) underwent 90-min dynamic ${ }^{11} \mathrm{C}$-erlotinib PET scans. One group of wild-type mice $(n=6)$ underwent 90 -min dynamic ${ }^{11} \mathrm{C}$-erlotinib PET scans at $20 \mathrm{~min}$ after intravenous pretreatment with the dual ABCB1/ABCG2 inhibitor elacridar $(10 \mathrm{mg} / \mathrm{kg})$. Additional groups of wild-type and Abcb1a/ $/ \mathrm{b}^{(-/-)} \mathrm{Abcg} 2^{(-/-)}$mice ( $n=4$ per group) underwent 90 -min dynamic ${ }^{11} \mathrm{C}$-erlotinib PET scans, in which a pharmacologic dose of unlabeled erlotinib $(10 \mathrm{mg} / \mathrm{kg})$ was coinjected with ${ }^{11} \mathrm{C}$-erlotinib. The choice of pharmacologic dose was based on previous work by Petrulli et al. (5).

\section{PET/MR Imaging}

Animals were preanesthetized in an induction chamber using isoflurane $\left(2.5 \%-3.5 \%\right.$ in oxygen) and placed on a heated animal bed $\left(38^{\circ} \mathrm{C}\right)$, and the lateral tail vein was cannulated. Anesthesia and warming were maintained for the whole imaging period. Anatomic MR imaging was performed on a 1-T benchtop MR imaging system (ICON; Bruker BioSpin $\mathrm{GmbH}$ ) using a modified 3-dimensional T1-weighted gradient echo sequence (T1-fast low angle shot). After MR imaging, the animal bed was transferred into the gantry of a microPET scanner (Focus 220; Siemens Medical Solutions) and a 10-min transmission scan using a ${ }^{57}$ Co point source was recorded. Subsequently, ${ }^{11} \mathrm{C}$-erlotinib $(27 \pm 8 \mathrm{MBq}, 2 \pm 1 \mathrm{nmol}$, $0.10 \mathrm{~mL}, n=29$ ) was administered as an intravenous bolus over $1 \mathrm{~min}$, and a 90-min dynamic PET scan (energy window, 250-750 keV; timing window, $6 \mathrm{~ns}$ ) was initiated at the start of radiotracer injection.

\section{Postimaging Procedures}

At the end of PET, a terminal blood sample was withdrawn under isoflurane anesthesia from the retroorbital sinus vein and animals were sacrificed by cervical dislocation. Aliquots of blood and plasma were measured for radioactivity in a $\gamma$ counter (Wizard 1470; Perkin-Elmer). The measured radioactivity data were corrected for radioactive decay and expressed as standardized uptake value $(\mathrm{SUV}=$ (radioactivity per g/injected radioactivity) $\times$ body weight).

\section{PET Data Analysis}

Dynamic emission PET data were sorted into 25 frames, which incrementally increased in time length from $5 \mathrm{~s}$ to $20 \mathrm{~min}$. Images were reconstructed using Fourier rebinning of the 3-dimensional sinograms, followed by filtered backprojection with a ramp filter resulting in a voxel size of $0.4 \times 0.4 \times 0.796 \mathrm{~mm}^{3}$. The standard data-correction protocol (normalization, injection decay correction, and attenuation correction) was applied to the data. Whole brain, right lung, left ventricle of the heart, left kidney, liver, gallbladder, intestine, and urinary bladder were manually outlined on coregistered PET/MR images using the image analysis software AMIDE, and time-activity curves, expressed as SUV, were derived. It was assumed that the sum of radioactivity in the gallbladder and the intestine represented radioactivity in the bile excreted from the liver. From the time-activity curves, the area under the curve from time 0 to $90 \mathrm{~min}$ (AUC) was calculated using Prism 5.0 software (GraphPad Software).

\section{Integration Plot Analysis}

A previously described graphical analysis approach (integration plot) $(14,15)$ was used to estimate cerebral, hepatic, renal, and pulmonary uptake clearances $\left(\mathrm{CL}_{\text {uptake,brain }}, \mathrm{CL}_{\text {uptake,liver }}, \mathrm{CL}_{\text {uptake,kidney, }}\right.$ and $\mathrm{CL}_{\text {uptake,lung, }}$, respectively) and biliary excretion clearance $\left(\mathrm{CL}_{\text {bile }}\right)$ of ${ }^{11} \mathrm{C}$-erlotinib. Details are given in the supplemental materials (available at http://jnm.snmjournals.org).

\section{Analysis of Metabolites and Plasma Protein Binding}

Radiolabeled metabolites of ${ }^{11} \mathrm{C}$-erlotinib were measured at $25 \mathrm{~min}$ after injection with radio-thin-layer chromatography in wild-type mice, pretreated either with vehicle or with elacridar $(10 \mathrm{mg} / \mathrm{kg})$, and in Abcb1 $\mathrm{a} / \mathrm{b}^{(-1-)} \mathrm{Abcg} 2^{(-1-)}$ mice as described in the supplemental materials. The plasma protein binding of ${ }^{11} \mathrm{C}$-erlotinib was determined as described in the supplemental materials.

\section{Statistical Analysis}

Differences between groups were analyzed by 1-way ANOVA followed by a Bonferroni multiple-comparison test using Prism 5.0 software. The level of statistical significance was set to a $P$ value of less than 0.05. All values are given as mean $\pm \mathrm{SD}$.

\section{RESULTS}

\section{Effect of Abcb1a/b or Abcg2 Knockout on ${ }^{11} \mathrm{C}$-Erlotinib Disposition}

We obtained ${ }^{11} \mathrm{C}$-erlotinib PET/MR scans in wild-type, Abcbla/b $\mathrm{b}^{(-/-)}, \operatorname{Abcg} 2^{(-/-)}$, and Abcb1a/b ${ }^{(-/-)} \mathrm{Abcg} 2^{(-/-)}$mice. Distribution of ${ }^{11} \mathrm{C}$-erlotinib to the brain was low in wild-type mice and significantly higher in $\mathrm{Abcb} 1 \mathrm{a} / \mathrm{b}^{(-/-)} \mathrm{Abcg} 2^{(-/-)}$mice (brain AUC, wild-type: $18.5 \pm 1.3$, Abcb1a/b $\mathrm{b}^{(-/-)} \mathrm{Abcg} 2^{(-1-)}$ : $51.0 \pm 8.1, P<0.001$ ) (Figs. 1 and $2 \mathrm{~A}$ ). In mice lacking only Abcb1a/b or Abcg2, brain AUCs were only moderately and not significantly increased as compared with wild-type mice $\left.\left(\mathrm{Abcb1a} / \mathrm{b}^{(-)}, 24.7 \pm 0.7 ; \mathrm{Abcg} 2^{(-/-}\right), 25.9 \pm 0.7\right)$. To quantitatively evaluate brain distribution of ${ }^{11} \mathrm{C}$-erlotinib, we used a graphical analysis approach (integration plot) to estimate the rate constants for transfer of radioactivity from blood into brain (cerebral uptake clearance, $\mathrm{CL}_{\text {uptake,brain }}$ ). $\mathrm{CL}_{\text {uptake,brain }}$ corresponds to $K_{1}$ from kinetic modeling of PET data, which has been shown in previous work to be a sensitive parameter of efflux transporter function at the $\mathrm{BBB}$ 


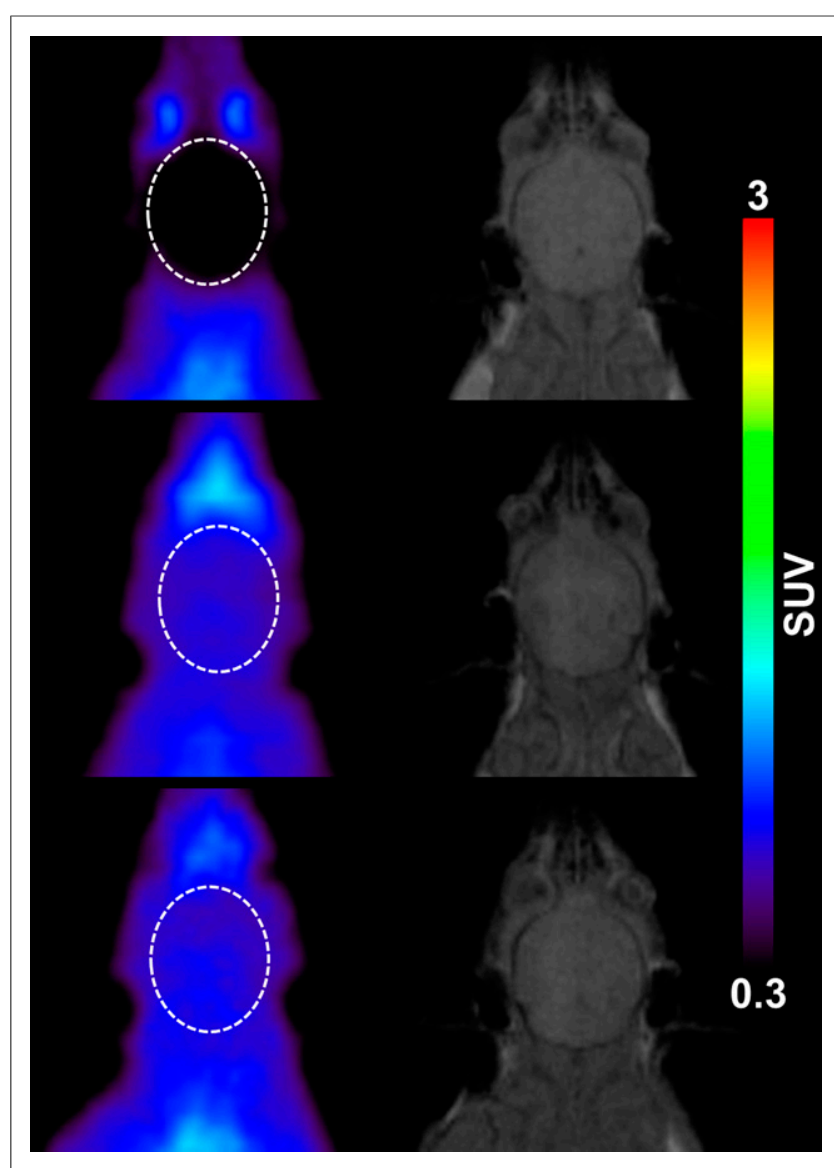

FIGURE 1. Representative coronal ${ }^{11} \mathrm{C}$-erlotinib PET summation images (0-90 $\mathrm{min}$ ) and corresponding planes of T1-weighted gradient echo MR images of brain region in wild-type mouse (upper), wild-type mouse pretreated $20 \mathrm{~min}$ before PET with elacridar ( $10 \mathrm{mg} / \mathrm{kg}$ ) (middle), and $\mathrm{Abcb} 1 \mathrm{a} / \mathrm{b}^{(-/)} \mathrm{Abcg} 2^{(--)}$mouse (bottom). Brain is highlighted with white broken line.

$(15,16)$. To determine the radioactivity concentrations in blood, we generated an image-derived blood curve by placing a region of interest into the left ventricle of the heart. Radioactivity concentrations measured with PET in the heart showed good correlation $(r=0.942$, $P<0.0001$ ) with blood radioactivity concentrations measured at the end of PET in a $\gamma$ counter (Supplemental Fig. 1). In Supplemental Figure 2, representative integration plots are shown. In Supplemental Table 1, uptake and excretion clearances in different organs of all studied mouse groups are given.

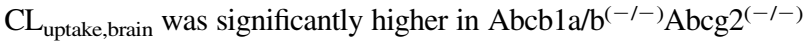
than in wild-type mice (Supplemental Fig. 2A) but not significantly increased in Abcbla $/ \mathrm{b}^{(-/-)}$and $\mathrm{Abcg} 2^{(-/-)}$mice (Fig. 2C). The absence of Abcg2 had a pronounced effect on biliary excretion of radioactivity from the liver into the intestine (Figs. 3 and 4C). Both in $\mathrm{Abcg} 2^{(-/-)}$and in Abcb1a/ $\mathrm{b}^{(-/-)} \mathrm{Abcg} 2^{(-/-)}$mice, biliary excretion clearances $\left(\mathrm{CL}_{\mathrm{bile}}\right)$ were significantly reduced as compared with wild-type mice (Supplemental Fig. 2B; Fig. 5C), resulting in prolonged liver retention of radioactivity (Fig. 3). $\operatorname{Abcg} 2^{(-/-)}$and Abcb1a/b $\mathrm{b}^{(-1-)} \mathrm{Abcg} 2^{(-/-)}$mice showed in contrast to all other mouse groups urinary excretion of radioactivity (Figs. 3 and 4D). In the lungs, no significant differences in ${ }^{11} \mathrm{C}$-erlotinib distribution were observed between wild-type and transporter knockout mice (Supplemental Fig. 3).
Differences in ${ }^{11} \mathrm{C}$-Erlotinib Disposition After Administration of Microdose and Pharmacologic Dose

We acquired ${ }^{11} \mathrm{C}$-erlotinib PET/MR scans in wild-type and $\mathrm{Abcb} 1 \mathrm{a} / \mathrm{b}^{(-/-)} \mathrm{Abcg} 2^{(-/-)}$mice receiving either a microdose or a pharmacologic dose $(10 \mathrm{mg} / \mathrm{kg})$ of erlotinib. ${ }^{11} \mathrm{C}$-erlotinib distribution was visually different for the 2 dose groups (Fig. 3). Blood radioactivity concentrations were significantly higher $(P<0.001)$ for the pharmacologic dose than for the microdose (heart AUC,

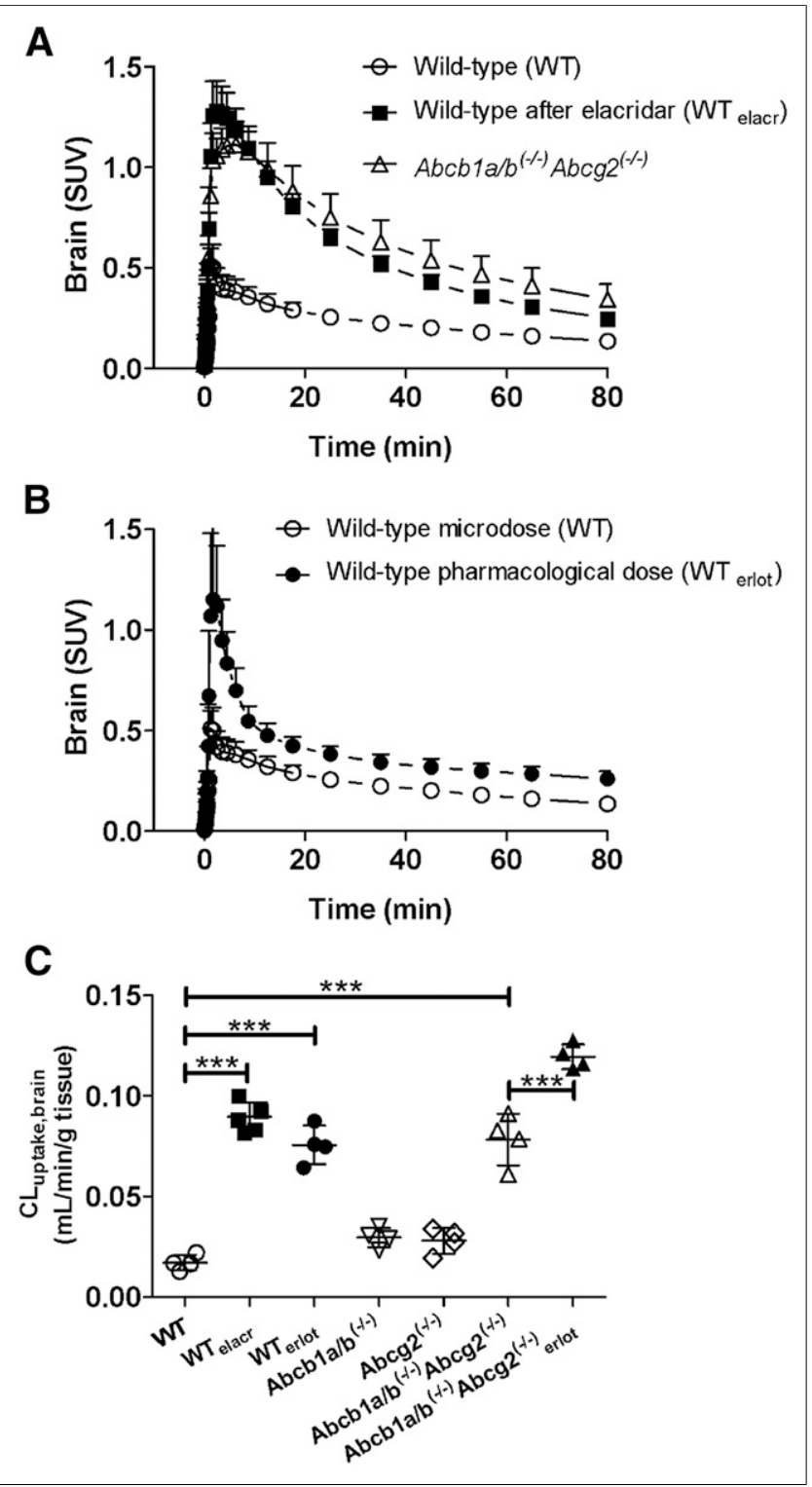

FIGURE 2. (A) Time-activity curves (mean SUV \pm SD) of ${ }^{11} \mathrm{C}$-erlotinib in whole brain of wild-type mice, Abcb1 $\mathrm{a} / \mathrm{b}^{(-/)} \mathrm{Abcg} 2^{(-/)}$mice, and wildtype mice pretreated $20 \mathrm{~min}$ before PET with elacridar $(10 \mathrm{mg} / \mathrm{kg})$. (B) Time-activity curves (mean SUV $\pm \mathrm{SD}$ ) of ${ }^{11} \mathrm{C}$-erlotinib in whole brain of wild-type mice injected with microdose or pharmacologic dose of erlotinib $(10 \mathrm{mg} / \mathrm{kg})$. (C) Cerebral uptake clearances of ${ }^{11} \mathrm{C}$-erlotinib in wild-type (WT) mice, wild-type mice pretreated with elacridar $(10 \mathrm{mg} / \mathrm{kg}, 20 \mathrm{~min}$ before PET) $\left(\mathrm{WT}_{\text {elacr }}\right)$, wild-type mice coinjected with pharmacologic dose of unlabeled erlotinib $(10 \mathrm{mg} / \mathrm{kg})\left(\mathrm{WT}_{\text {erlot }}\right), \mathrm{Abcb} 1 \mathrm{a} / \mathrm{b}^{(-/-)} \mathrm{mice}, \mathrm{Abcg} 2^{(-/)}$ mice, Abcb1a/b $\mathrm{b}^{(-/)} \mathrm{Abcg} 2^{(-/)}$mice, and Abcb1a/b/ $\mathrm{b}^{(-)} \mathrm{Abcg} 2^{(-/)}$mice coinjected with pharmacologic dose of unlabeled erlotinib $(10 \mathrm{mg} / \mathrm{kg})$ (Abcb1a/b(-/) $\mathrm{Abcg}^{(-/-)}$erlot). ${ }^{* * *} P<0.001,1$-way ANOVA with Bonferroni multiple-comparison test. 


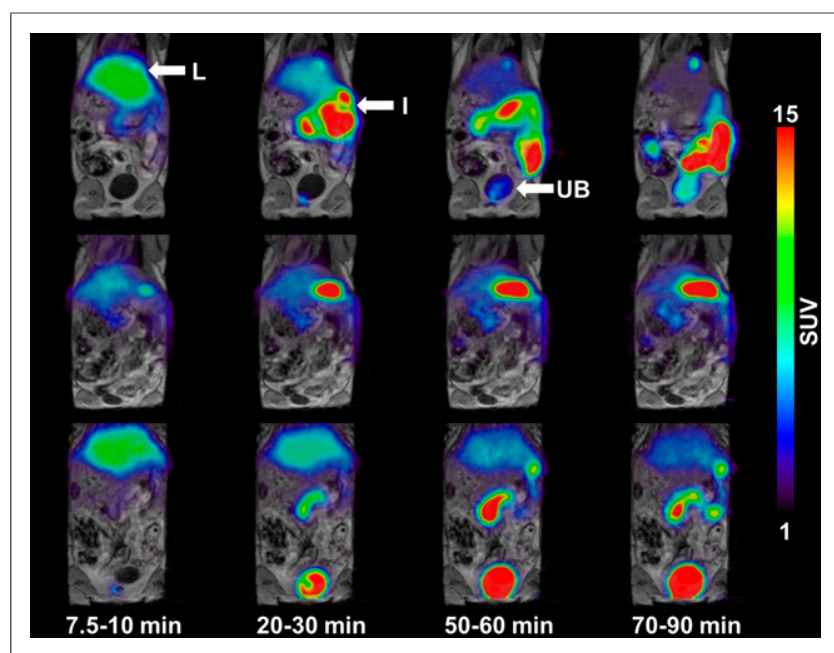

FIGURE 3. Serial coronal whole-body PET/MR images of ${ }^{11} \mathrm{C}$-erlotinib in wild-type mouse (upper), wild-type mouse coinjected with pharmacologic dose of unlabeled erlotinib $\left(10 \mathrm{mg} / \mathrm{kg}\right.$ ) (middle), and Abcb1a/b(-/) Abcg $2^{(-/)}$ mouse (bottom). Anatomic structures are indicated by arrows: I = intestine; $\mathrm{L}=$ liver; $\mathrm{UB}=$ urinary bladder.

wild-type microdose: $91.0 \pm 2.4$, pharmacologic dose: $135.8 \pm$ 13.3; Abcb1a/ $\mathrm{b}^{(-1-)} \mathrm{Abcg} 2^{(-1-)}$ microdose: $105.6 \pm 19.2$, pharmacologic dose: $149.6 \pm 7.2$ ). In the brain, AUCs and $\mathrm{CL}_{\text {uptake,brain }}$ were significantly higher in animals receiving the pharmacologic dose (Fig. 2C), both in wild-type mice (4.5-fold increase in $\mathrm{CL}_{\text {uptake,brain }}$ ) and in Abcb1a/b $\mathrm{b}^{(-)} \mathrm{Abcg} 2^{(-1-)}$ mice (1.5-fold increase in $\mathrm{CL}_{\text {uptake,brain }}$ ).

In the liver and kidneys, $\mathrm{CL}_{\text {uptake }}$ was significantly lower for the pharmacologic dose than for the microdose, both in wild-type mice and in Abcb1a/ $\mathrm{b}^{(-/-)} \mathrm{Abcg} 2^{(-/-)}$mice (Figs. 5A and 5B). In the liver of wild-type but not $\mathrm{Abcb} 1 \mathrm{a} / \mathrm{b}^{(-1-)} \mathrm{Abcg} 2^{(-1-)}$ mice, $\mathrm{CL}_{\text {bile }}$ was significantly lower for the pharmacologic dose than for the microdose (Figs. $4 \mathrm{C}$ and $5 \mathrm{C}$ ). In Abcb1a/b ${ }^{(-/-)} \mathrm{Abcg} 2^{(-/-)}$ but not in wild-type mice, radioactivity excreted into urine was significantly lower in animals injected with a pharmacologic dose than with a microdose (urinary bladder AUC, wild-type microdose: $260 \pm 65$, pharmacologic dose: $407 \pm 258 ; \mathrm{Abcb1a} / \mathrm{b}^{(-l-)} \mathrm{Abcg} 2^{(-1-)}$ microdose: $1,888 \pm 370$, pharmacologic dose: $41 \pm 9, P<$ 0.001). In the lungs, $\mathrm{CL}_{\text {uptake }}$ was significantly increased in animals receiving the pharmacologic dose, both in wild-type and in Abcb1a/b $\mathrm{b}^{(-/-)} \mathrm{Abcg} 2^{(-/-)}$mice (Supplemental Fig. 3).

\section{Effect of Elacridar on ${ }^{11} \mathrm{C}$-Erlotinib Disposition}

We assessed the effect of the dual ABCB1/ABCG2 inhibitor elacridar on tissue distribution of ${ }^{11} \mathrm{C}$-erlotinib in wild-type mice, which underwent ${ }^{11} \mathrm{C}$-erlotinib PET scans after intravenous pretreatment with elacridar $(10 \mathrm{mg} / \mathrm{kg})$. Elacridar administration resulted in a significant increase in brain AUCs $(45.2 \pm 3.3$ vs.

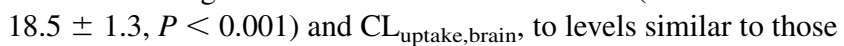
in Abcb1a/b $\mathrm{b}^{(-/-)} \mathrm{Abcg} 2^{(-/-)}$mice (Figs. 2A and $2 \mathrm{C}$ ). In the other studied organs, elacridar pretreatment exerted no significant effect on ${ }^{11} \mathrm{C}$-erlotinib distribution (Fig. 5) except for the lung (Supplemental Fig. 3), in which $\mathrm{CL}_{\text {uptake,lung was significantly increased in }}$ elacridar-treated as compared with untreated mice.

\section{Metabolism and Plasma Protein Binding of ${ }^{11} \mathrm{C}$-Erlotinib}

Radiolabeled metabolites of ${ }^{11} \mathrm{C}$-erlotinib were assessed with radio-thin-layer chromatography in plasma, brain, liver, bile, and urine of vehicle-treated and elacridar-treated wild-type mice, and Abcb1a/ $\mathrm{b}^{(-1-)} \mathrm{Abcg} 2^{(-1-)}$ mice (Supplemental Table 2). In plasma and brain, most radioactivity was in the form of unmetabolized ${ }^{11} \mathrm{C}$-erlotinib. In liver and bile, approximately one third to one half of radioactivity was in the form of unmetabolized ${ }^{11} \mathrm{C}$-erlotinib, whereas almost no unmetabolized ${ }^{11} \mathrm{C}$-erlotinib was detected in urine (Supplemental Table 2). No significant differences were observed between the 3 studied mouse groups in percentage of unchanged ${ }^{11} \mathrm{C}$-erlotinib in different organs and liquids. The percentage of ${ }^{11} \mathrm{C}$-erlotinib that was not bound to plasma proteins was low $(<1 \%)$ and independent of the presence or absence of elacridar or unlabeled erlotinib (Supplemental Table 3).

\section{DISCUSSION}

Among several different radiolabeled reversible and irreversible TKIs tested for PET imaging of receptor tyrosine kinases, ${ }^{11} \mathrm{C}$-erlotinib has emerged as a promising candidate tracer to distinguish responders from nonresponders to treatment with EGFR-targeted TKIs (e.g., gefitinib, erlotinib) (17). Preclinical as well as clinical data indicate that ${ }^{11} \mathrm{C}$-erlotinib binds specifically to EGFR with activating mutations (e.g., delE746-A750, L858R), whereas it lacks specific binding to wild-type EGFR (2-6). Preclinical studies have shown that specific binding of ${ }^{11} \mathrm{C}$-erlotinib to mutated EGFR is reduced when pharmacologic doses of erlotinib are coadministered, presumably due to saturation of EGFR-specific binding sites $(5,6)$. Consequently, ${ }^{11} \mathrm{C}$-erlotinib PET imaging in patients undergoing TKI treatment may prohibit the visualization of EGFR-specific binding in tumors. In addition to binding to mutated EGFR, the known interaction of erlotinib with $\mathrm{ABC}$ and solute carrier (SLC) transporters $(8,9,18)$ may exert an influence on the distribution of ${ }^{11} \mathrm{C}$-erlotinib to tumoral and nontumoral tissue. These transporters are widely expressed all over the body, such as at blood-tissue barriers (e.g., BBB or blood-testis barrier) and in excretory organs (liver, kidney, intestine), and may also become overexpressed in multidrug-resistant tumors in which they restrict intracellular distribution of anticancer agents $(12,13)$. The transport of drugs by ABC and SLC transporters is of concern because this may lead to interindividual variability in

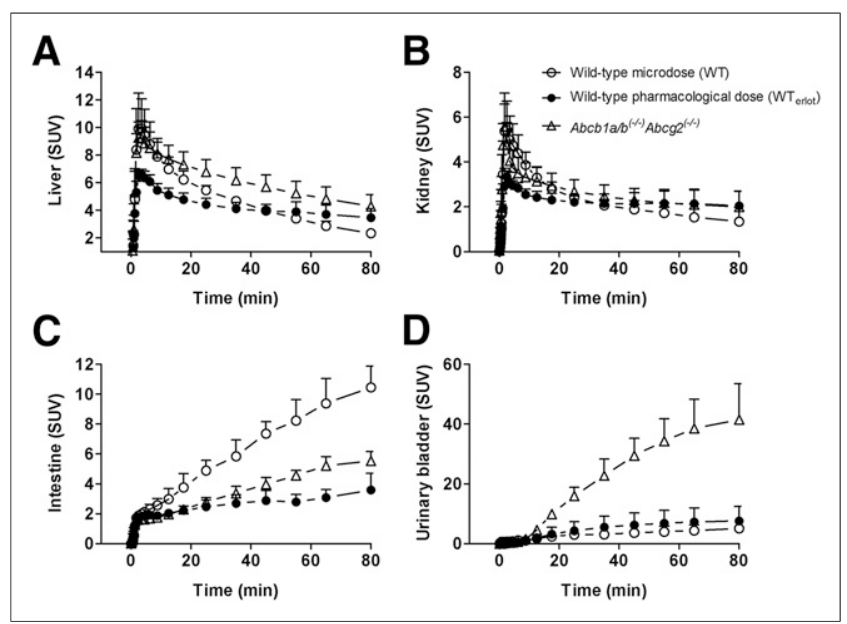

FIGURE 4. Time-activity curves (mean SUV \pm SD) of ${ }^{11} \mathrm{C}$-erlotinib in liver (A), kidney (B), intestine (C), and urinary bladder (D) of wild-type mice injected with microdose (WT) or pharmacologic dose of erlotinib $(10 \mathrm{mg} / \mathrm{kg})\left(\mathrm{WT}_{\text {erlot }}\right)$ and of $\mathrm{Abcb} 1 \mathrm{a} / \mathrm{b}^{(-/)} \mathrm{Abcg} 2^{(-/)}$mice. 
drug pharmacokinetics due to genetic polymorphisms or to transporter-mediated drug-drug interactions potentially causing adverse reactions (12). Moreover, dose-dependent partial saturation of drug transporters may lead to nonlinear pharmacokinetics of transporter substrates, which may result in differences in organ distribution between a microdose and therapeutic dose.

In the present study, we assessed the effect of ABCG2 and $\mathrm{ABCB} 1$ on whole-body distribution and excretion of ${ }^{11} \mathrm{C}$-erlotinib and investigated whether PET imaging with a microdose of ${ }^{11} \mathrm{C}$-erlotinib is capable of predicting the organ distribution of a therapeutic erlotinib dose. We addressed these questions by performing small-animal PET/MR experiments with ${ }^{11} \mathrm{C}$-erlotinib without and with coinjection of a pharmacologic dose of unlabeled erlotinib (10 mg/kg) in wild-type and Abcb1a/b or Abcg2 knockout mice. Previous work has shown that $\mathrm{Abcb1} \mathrm{a} / \mathrm{b}^{(-/-)}, \mathrm{Abcg} 2^{(-/-)}$, and $\mathrm{Abcb} 1 \mathrm{a} / \mathrm{b}^{(-/-)} \mathrm{Abcg} 2^{(-1-)}$ mice lack compensatory alterations in expression levels of other ABC and SLC transporters and are useful tools to study the effects of ABCB1 and ABCG2 on drug disposition (19). A potential limitation of using mice is their small blood volume, which prohibits arterial blood sampling, which is needed for quantitative analysis of PET data. We overcame this problem by generating an image-derived blood curve from the left ventricle of the heart. The use of a previously described graphical analysis approach (integration plot) (Supplemental Fig. 2) (14,15) allowed us to estimate the rate constants for transfer of radioactivity from blood into different organs (brain, liver, kidney, lungs) $\left(\mathrm{CL}_{\text {uptake }}\right)$ as well as for transfer of radioactivity from liver into the intestine $\left(\mathrm{CL}_{\text {bile }}\right)$ to quantitatively evaluate the effects of Abcb1a/b and Abcg2 on ${ }^{11} \mathrm{C}$-erlotinib disposition (Figs. 2C and 5; Supplemental Table 1).

We were able to confirm earlier data that brain distribution of erlotinib is restricted by $\mathrm{Abcb} 1 \mathrm{a} / \mathrm{b}$ and $\mathrm{Abcg} 2(8,10,11)$. It has now been documented for many dual ABCB1/ABCG2 substrates that these 2 transporters are capable of mutually compensating their function when 1 transporter is knocked out or inhibited $(20,21)$. This phenomenon causes only small increases in brain distribution of ABCB1/ABCG2 substrates when only 1 transporter is absent and disproportionally large increases when both transporters are absent, as was the case for ${ }^{11} \mathrm{C}$-erlotinib (Fig. 2C). Importantly, we could show that radioactivity in the brain after injection of ${ }^{11} \mathrm{C}$-erlotinib is mainly in the form of unmetabolized ${ }^{11} \mathrm{C}$-erlotinib (Supplemental Table 2) thus making ${ }^{11} \mathrm{C}$-erlotinib PET suitable to assess the effect of $\mathrm{ABCB} 1$ and $\mathrm{ABCG} 2$ on ${ }^{11} \mathrm{C}$-erlotinib brain distribution. It is now known that most currently available TKIs (e.g., sorafenib, gefitinib, sunitinib) are dual ABCB1/ABCG2 substrates resulting in low brain distribution $(20,21)$. This is of concern as poor BBB penetration may render these drugs ineffective in the treatment of primary or secondary brain tumors (e.g., gliomas, NSCLC brain metastases) $(11,22)$. Pharmacologic inhibition of ABCB1 and ABCG2 has been suggested as a promising approach to enhance brain distribution of TKIs and thereby increase their efficacy to treat brain tumors $(20,22)$. However, a limitation in realizing this therapeutic concept is the current lack of clinically usable, marketed dual ABCB1/ ABCG2 inhibitors. The most potent dual ABCB1/ABCG2 inhibitor known to date is elacridar, which has shown great promise in enhancing brain distribution of dual ABCB1/ABCG2 substrates in preclinical studies (20-22). We found that $10 \mathrm{mg}$ of elacridar per kilogram given intravenously 20 min before ${ }^{11} \mathrm{C}$-erlotinib injection can increase brain distribution of ${ }^{11} \mathrm{C}$-erlotinib to an extent similar to that in $\mathrm{Abcb} 1 \mathrm{a} / \mathrm{b}^{(-/-)} \mathrm{Abcg} 2^{(-/-)}$mice, indicating complete inhibition of Abcb1a/b and Abcg2 at the BBB (Figs. 1, 2A, and 2C). An oral formulation of elacridar has been used in clinical studies in
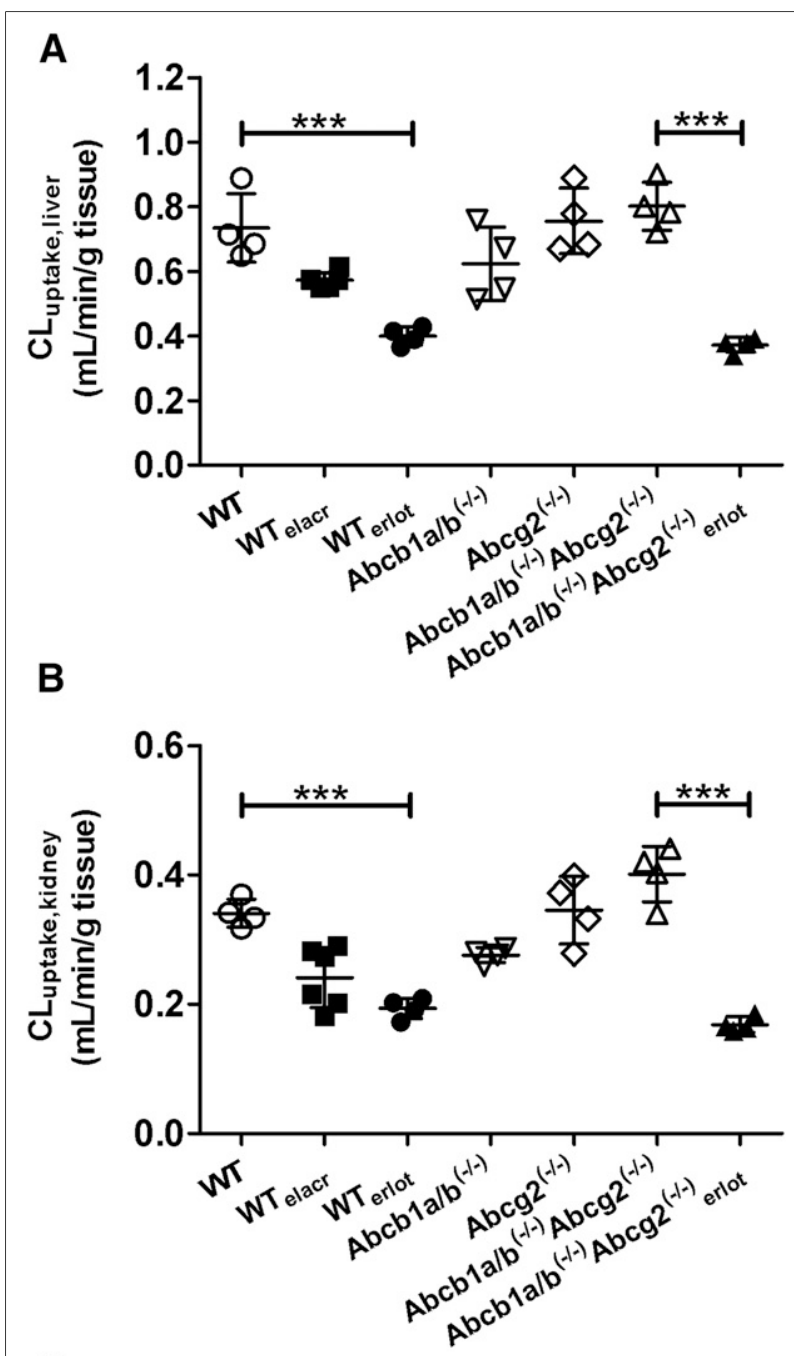

C

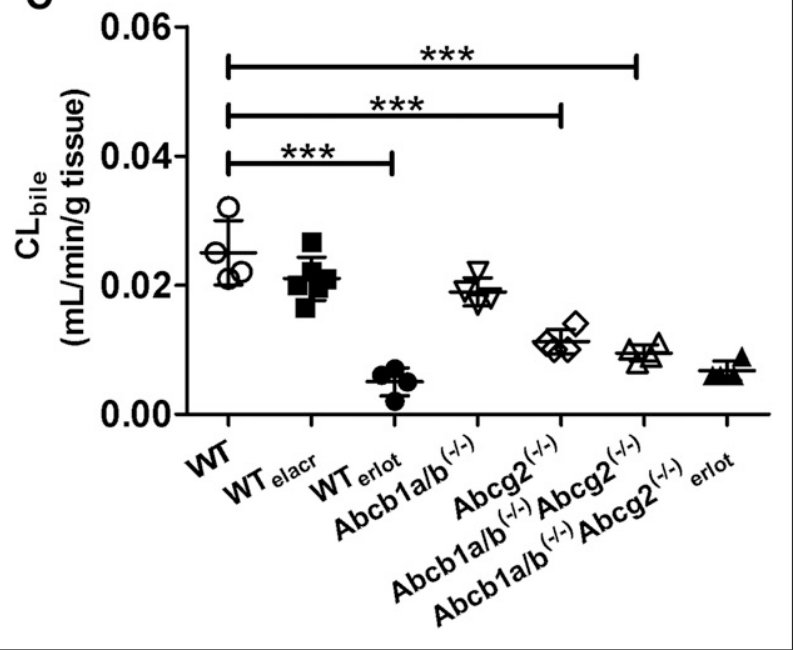

FIGURE 5. Hepatic (A) and renal (B) uptake clearances and biliary (C) excretion clearances of ${ }^{11} \mathrm{C}$-erlotinib in wild-type mice (WT), wild-type mice pretreated with elacridar ( $10 \mathrm{mg} / \mathrm{kg}, 20 \mathrm{~min}$ before PET) $\left(\mathrm{WT}_{\text {elacr }}\right.$ ), wild-type mice coinjected with pharmacologic dose of unlabeled erlotinib $(10 \mathrm{mg} / \mathrm{kg})$ $\left(\mathrm{WT}_{\text {erlot }}\right), \mathrm{Abcb} 1 \mathrm{a} / \mathrm{b}^{(-/)}$mice, Abcg2 $2^{(-/)}$mice, Abcb1a/b $\mathrm{b}^{(-)}$Abcg2 $2^{(-/)}$ mice, and $\mathrm{Abcb} 1 \mathrm{a} / \mathrm{b}^{(-/)} \mathrm{Abcg} 2^{(-/)}$mice coinjected with pharmacologic dose of unlabeled erlotinib $(10 \mathrm{mg} / \mathrm{kg})\left(\mathrm{Abcb} 1 \mathrm{a} / \mathrm{b}^{(-/)} \mathrm{Abcg} 2^{(-/)}\right.$erlot)$)$. ${ }^{\star \star \star} P<0.001$, 1-way ANOVA with Bonferroni multiple-comparison test. 
cancer patients to increase oral bioavailability of concomitantly administered anticancer drugs (e.g., topotecan) by inhibition of ABCG2 and ABCB1 in the intestine (23). However, as the oral bioavailability of elacridar is low, resulting in low plasma concentrations, future use of elacridar as an inhibitor of $\mathrm{ABCB} 1$ and $\mathrm{ABCG} 2$ at the human $\mathrm{BBB}$ will most likely require an intravenous formulation of the drug (22).

Intriguingly, we could show that the coinjection of a pharmacologic dose of erlotinib results in increases in $\mathrm{CL}_{\text {uptake,brain }}$ of ${ }^{11} \mathrm{C}$-erlotinib similar to those in elacridar-treated animals (Fig. 2C). This increase suggests that erlotinib may be of potential use as a clinically available inhibitor of $\mathrm{ABCB} 1$ and $\mathrm{ABCG} 2$ to enhance brain distribution of other dual ABCB1/ABCG2 substrates (24). After a comparably high initial brain uptake, washout of radioactivity was faster from the brains of erlotinib-coinjected wild-type mice than from Abcb1a/ $\mathrm{b}^{(-1-)} \mathrm{Abcg} 2^{(-1-)}$ mice (Figs. $2 \mathrm{~A}$ and $2 \mathrm{~B}$ ), which indicated that the $\mathrm{Abcb} 1 \mathrm{a} / \mathrm{b} / \mathrm{Abcg} 2$ inhibitory effect of erlotinib is reversible. For future use of erlotinib as an ABCB1/ABCG2 inhibitor in human PET studies, it may therefore be preferable to administer erlotinib as a continuous intravenous infusion that is maintained for the duration of the PET scan, as we have done in a previous PET study with the ABCB1 inhibitor tariquidar (16). Importantly, we could demonstrate that brain distribution of ${ }^{11} \mathrm{C}$-erlotinib was nonlinear between a microdose and a pharmacologic dose - that is, for the pharmacologic dose brain exposure (Fig. 2B) and $\mathrm{CL}_{\text {uptake,brain }}$ (Fig. 2C) were significantly higher.

We also found an influence of Abcg2 and Abcb1 on the distribution of ${ }^{11} \mathrm{C}$-erlotinib to peripheral organs. Our data clearly indicated that ${ }^{11} \mathrm{C}$-erlotinib or its radiolabeled metabolites undergo hepatobiliary excretion into the intestine mediated by Abcg 2 and Abcb1a/b (Fig. 4C). The absence of both Abcg2 and Abcb1a/b caused a 2.6-fold reduction in $\mathrm{CL}_{\text {bile }}$ (Fig. 5C), suggesting that ${ }^{11} \mathrm{C}$-erlotinib PET may be useful to study the functional activity of $\mathrm{Abcg} 2$ and $\mathrm{Abcb} 1 \mathrm{a} / \mathrm{b}$ in the liver. Interestingly, coadministration of a pharmacologic dose of erlotinib caused a 5-fold reduction in $\mathrm{CL}_{\text {bile }}$ in wild-type mice (Fig. 5C), indicating that the influence of Abcg 2 and Abcb1a/b on hepatobiliary excretion of erlotinib may be more important when a microdose is administered. However, the determination of $\mathrm{CL}_{\text {bile }}$ was based on the assumption that excretion of radioactivity into the intestine occurs exclusively via bile and not by direct secretion from blood. To confirm this assumption, it would be necessary to examine bile duct-cannulated mice, which is technically challenging and which was not done in the present study.

In the absence of Abcg2 (i.e., in $\mathrm{Abcg} 2^{(-/-)}$and Abcb1a/ $\mathrm{b}^{(-/-)}$ Abcg $2^{(-1-)}$ mice), a shift from hepatobiliary to renal excretion of ${ }^{11} \mathrm{C}$-erlotinib was observed, which otherwise showed negligible excretion into urine (Figs. 3 and 4D). This suggested that transporters other than $\mathrm{Abcg} 2$ and $\mathrm{Abcb} 1 \mathrm{a} / \mathrm{b}$ accounted for urinary excretion of radioactivity. As radio-thin-layer chromatography analysis showed that most radioactivity in urine was in the form of radiolabeled metabolites (Supplemental Table 2) it appears likely that not ${ }^{11} \mathrm{C}$-erlotinib itself but one or several radiolabeled metabolites underwent active transport at the brush border membrane of kidney proximal tubule cells, with multidrug resistanceassociated proteins 4 and 2 (Abcc 4 and Abcc2) as the most likely candidate transporters.

Both in the liver and in the kidneys, $\mathrm{CL}_{\text {uptake }}$ was significantly lower for the pharmacologic dose than for the microdose (Figs. 4A, $4 \mathrm{~B}, 5 \mathrm{~A}$, and $5 \mathrm{~B}$ ). This suggests partial saturation of basolateral uptake transporters in hepatocytes and kidney cells, such as organic anion transporting polypeptides (e.g., OATP2B1, SLCO2B1) and organic anion transporter 3 (SLC22A7). This assumption is in line with previous findings that TKIs including erlotinib are competitive inhibitors of these SLC transporters (18). Partial saturation of uptake transporters most likely also accounted for the significantly higher blood AUCs for the pharmacologic dose than the microdose. An increase in systemic exposure of drugs on inhibition of basolateral uptake transporters in hepatocytes has been observed for several different drugs (25).

Lung tissue can be considered as a target tissue for treatment of NSCLC with erlotinib. It is known that several different $\mathrm{ABC}$ and SLC transporters are expressed in lung tissue (e.g., multidrug resistance-associated protein 1 [ABCC1] and ABCG2), where they control pulmonary absorption of inhaled drugs as well as transport of drugs from epithelial cells to the circulating blood (26). We found no influence of Abcb1a/b and Abcg2 on the distribution of ${ }^{11} \mathrm{C}$-erlotinib to the lung (Supplemental Fig. 3). However, the coinjection of a pharmacologic dose caused significant increases in $\mathrm{CL}_{\text {uptake,lung, pointing }}$ to partial saturation of other unknown efflux transporters. Interestingly, elacridar led also to an increase in $\mathrm{CL}_{\text {uptake,lung, but it is not }}$ known by which mechanism.

Our findings are clinically relevant in that they suggest that future therapy guidance with ${ }^{11} \mathrm{C}$-erlotinib in tumor patients needs to take into account the influence of drug transporters on ${ }^{11} \mathrm{C}$-erlotinib disposition. Concomitant treatment of tumor patients with therapeutic doses of erlotinib or other TKIs may lead to partial saturation of drug transporters, which could cause changes in ${ }^{11} \mathrm{C}$-erlotinib PET signal in the tumor, which may be unrelated to treatment response or the mutational status of EGFR. However, because a standard oral therapeutic dose of erlotinib used in the clinic $(150 \mathrm{mg})$ is lower than the presently used pharmacologic dose in mice, it appears likely that less pronounced effects on drug transporters will be observed in humans.

\section{CONCLUSION}

ABCG2, ABCB1, and possibly other transporters influence the in vivo disposition of ${ }^{11} \mathrm{C}$-erlotinib and thereby affect its distribution to normal and potentially also tumor tissue. Saturable transport of erlotinib leads to nonlinear pharmacokinetics, which needs to be considered when attempting to predict the organ distribution of erlotinib in tumor patients using PET scans with a microdose of ${ }^{11} \mathrm{C}$-erlotinib. Inhibition of $\mathrm{ABCB} 1$ and $\mathrm{ABCG} 2$ is a promising approach to enhance brain distribution of erlotinib to increase its efficacy in the treatment of brain tumors.

\section{DISCLOSURE}

The costs of publication of this article were defrayed in part by the payment of page charges. Therefore, and solely to indicate this fact, this article is hereby marked "advertisement" in accordance with 18 USC section 1734 . This study was supported by the Lower Austria Corporation for Research and Education (NFB) (grant LS12-006) and by the Austrian Science Fund (FWF) (grant F 3513-B20). No other potential conflict of interest relevant to this article was reported.

\section{ACKNOWLEDGMENTS}

We thank Maria Zsebedics and Mathilde Löbsch for help in conducting the experiments and Stefan Oberndorfer (Universitätsklinikum 
St. Pölten) and Walter Berger and Maria Sibilia (both Medical University of Vienna) for helpful discussions.

\section{REFERENCES}

1. Hammerman PS, Janne PA, Johnson BE. Resistance to epidermal growth factor receptor tyrosine kinase inhibitors in non-small cell lung cancer. Clin Cancer Res. 2009;15:7502-7509.

2. Memon AA, Jakobsen S, Dagnaes-Hansen F, Sorensen BS, Keiding S, Nexo E. Positron emission tomography (PET) imaging with $\left[{ }^{11} \mathrm{C}\right]$-labeled erlotinib: a micro-PET study on mice with lung tumor xenografts. Cancer Res. 2009;69:873878.

3. Bahce I, Smit EF, Lubberink M, et al. Development of $\left[{ }^{11} \mathrm{C}\right]$ erlotinib positron emission tomography for in vivo evaluation of EGF receptor mutational status. Clin Cancer Res. 2013;19:183-193.

4. Slobbe P, Windhorst AD, Stigter-van Walsum M, et al. A comparative PET imaging study with the reversible and irreversible EGFR tyrosine kinase inhibitors $\left[{ }^{11} \mathrm{C}\right]$ erlotinib and $\left[{ }^{18} \mathrm{~F}\right]$ afatinib in lung cancer-bearing mice. EJNMMI Res. 2015;5:14.

5. Petrulli JR, Sullivan JM, Zheng MQ, et al. Quantitative analysis of $\left[{ }^{11} \mathrm{C}\right]$-erlotinib PET demonstrates specific binding for activating mutations of the EGFR kinase domain. Neoplasia. 2013;15:1347-1353.

6. Abourbeh G, Itamar B, Salnikov O, Beltsov S, Mishani E. Identifying erlotinibsensitive non-small cell lung carcinoma tumors in mice using $\left[{ }^{11} \mathrm{C}\right]$ erlotinib PET. EJNMMI Res. 2015;5:4.

7. Ling J, Johnson KA, Miao Z, et al. Metabolism and excretion of erlotinib, a small molecule inhibitor of epidermal growth factor receptor tyrosine kinase, in healthy male volunteers. Drug Metab Dispos. 2006;34:420-426.

8. Kodaira H, Kusuhara H, Ushiki J, Fuse E, Sugiyama Y. Kinetic analysis of the cooperation of P-glycoprotein (P-gp/Abcb1) and breast cancer resistance protein (Bcrp/Abcg2) in limiting the brain and testis penetration of erlotinib, flavopiridol, and mitoxantrone. J Pharmacol Exp Ther. 2010;333:788-796.

9. Shi Z, Peng XX, Kim IW, et al. Erlotinib (Tarceva, OSI-774) antagonizes ATPbinding cassette subfamily B member 1 and ATP-binding cassette subfamily G member 2-mediated drug resistance. Cancer Res. 2007;67:11012-11020.

10. de Vries NA, Buckle T, Zhao J, Beijnen JH, Schellens JH, van Tellingen O. Restricted brain penetration of the tyrosine kinase inhibitor erlotinib due to the drug transporters P-gp and BCRP. Invest New Drugs. 2012;30:443-449.

11. Agarwal S, Manchanda P, Vogelbaum MA, Ohlfest JR, Elmquist WF. Function of the blood-brain barrier and restriction of drug delivery to invasive glioma cells: findings in an orthotopic rat xenograft model of glioma. Drug Metab Dispos. 2013;41:33-39.
12. Giacomini KM, Huang SM, Tweedie DJ, et al. Membrane transporters in drug development. Nat Rev Drug Discov. 2010;9:215-236.

13. Gottesman MM, Fojo T, Bates SE. Multidrug resistance in cancer: role of ATPdependent transporters. Nat Rev Cancer. 2002;2:48-58.

14. Shingaki T, Hume WE, Takashima T, et al. Quantitative evaluation of mMate1 function based on minimally invasive measurement of tissue concentration using PET with $\left[{ }^{11} \mathrm{C}\right]$ metformin in mouse. Pharm Res. 2015;32:2538-2547.

15. Takano A, Kusuhara H, Suhara T, et al. Evaluation of in vivo P-glycoprotein function at the blood-brain barrier among MDR1 gene polymorphisms by using ${ }^{11} \mathrm{C}$-verapamil. J Nucl Med. 2006;47:1427-1433.

16. Bauer M, Karch R, Zeitlinger M, et al. Approaching complete inhibition of P-glycoprotein at the human blood-brain barrier: an (R)-[ $\left.{ }^{11} \mathrm{C}\right]$ verapamil PET study. J Cereb Blood Flow Metab. 2015;35:743-746.

17. Slobbe P, Poot AJ, Windhorst AD, van Dongen GA. PET imaging with smallmolecule tyrosine kinase inhibitors: TKI-PET. Drug Discov Today. 2012;17: $1175-1187$.

18. Johnston RA, Rawling T, Chan T, Zhou F, Murray M. Selective inhibition of human solute carrier transporters by multikinase inhibitors. Drug Metab Dispos. 2014;42:1851-1857.

19. Agarwal S, Uchida Y, Mittapalli RK, Sane R, Terasaki T, Elmquist WF. Quantitative proteomics of transporter expression in brain capillary endothelial cells isolated from P-glycoprotein (P-gp), breast cancer resistance protein (Bcrp), and P-gp/Bcrp knockout mice. Drug Metab Dispos. 2012;40:1164-1169.

20. Durmus S, Hendrikx JJ, Schinkel AH. Apical ABC transporters and cancer chemotherapeutic drug disposition. Adv Cancer Res. 2015;125:1-41.

21. Agarwal S, Hartz AM, Elmquist WF, Bauer B. Breast cancer resistance protein and P-glycoprotein in brain cancer: two gatekeepers team up. Curr Pharm Des. 2011;17:2793-2802.

22. van Tellingen O, Yetkin-Arik B, de Gooijer MC, Wesseling P, Wurdinger T, de Vries HE. Overcoming the blood-brain tumor barrier for effective glioblastoma treatment. Drug Resist Updat. 2015;19:1-12.

23. Kruijtzer CM, Beijnen $\mathrm{JH}$, Rosing $\mathrm{H}$, et al. Increased oral bioavailability of topotecan in combination with the breast cancer resistance protein and P-glycoprotein inhibitor GF120918. J Clin Oncol. 2002;20:2943-2950.

24. Minocha M, Khurana V, Qin B, Pal D, Mitra AK. Enhanced brain accumulation of pazopanib by modulating P-gp and Bcrp1 mediated efflux with canertinib or erlotinib. Int J Pharm. 2012;436:127-134.

25. Kusuhara H, Sugiyama Y. In vitro-in vivo extrapolation of transporter-mediated clearance in the liver and kidney. Drug Metab Pharmacokinet. 2009;24:37-52.

26. Sakamoto A, Matsumaru T, Yamamura N, et al. Quantitative expression of human drug transporter proteins in lung tissues: analysis of regional, gender, and interindividual differences by liquid chromatography-tandem mass spectrometry. $J$ Pharm Sci. 2013;102:3395-3406. 